\title{
PET Assessment of Myocardial Perfusion Reserve Inversely Correlates with Intravascular Ultrasound Findings in Angiographically Normal Cardiac Transplant Recipients
}

Yen-Wen Wu ${ }^{1-3}$, Ying-Hsien Chen ${ }^{3}$, Shoei-Shen Wang ${ }^{1,4}$, Hsiang-Yiang Jui ${ }^{1,3}$, Ruoh-Fang Yen ${ }^{1,2}$, Kai-Yuan Tzen ${ }^{1,2}$, Ming-Fong Chen ${ }^{1,3}$, and Chii-Ming Lee ${ }^{1,3}$

${ }^{I}$ National Taiwan University College of Medicine, Taipei, Taiwan; ${ }^{2}$ Department of Nuclear Medicine, National Taiwan University Hospital, Taipei, Taiwan; ${ }^{3}$ Division of Cardiology, Department of Internal Medicine, National Taiwan University Hospital, Taipei, Taiwan; and ${ }^{4}$ Department of Surgery, National Taiwan University Hospital, Taipei, Taiwan

Cardiac allograft vasculopathy (CAV) is the major determinant of long-term survival after heart transplantation. We aimed to evaluate the efficacy of PET as a noninvasive way to assess the early stages of CAV. Methods: Twenty-seven consecutive patients (20 men and 7 women; mean age \pm SD, $46 \pm 12$ y) who had normal results on coronary angiography and normal left ventricular systolic function (ejection fraction $\geq 60 \%$ ) were enrolled at $2.5 \pm 2.1$ y after transplantation. Myocardial blood flow (MBF) was assessed using dynamic ${ }^{13} \mathrm{~N}$-ammonia PET at rest and during adenosine-induced hyperemia, and myocardial perfusion reserve (MPR) was calculated as the ratio of hyperemic MBF to resting MBF. Regional ${ }^{13} \mathrm{~N}$-ammonia PET was assessed using a 5-point scoring system. The intravascular ultrasound (IVUS) measurements for the extent of intimal hyperplasia, including plaque volume index (calculated as [total plaque volume/total vessel volume] $\times 100 \%$ ) and maximum area of stenosis, were compared with MPR by linear regression analysis. Results: In 27 angiographically normal cardiac transplant recipients, MBF at rest and during adenosine stress and MPR of the left anterior descending artery distribution correlated strongly with the other 2 coronary artery distribution territories $(r \geq 0.97, P<0.0001)$. Summed stress score and summed difference score showed a moderate inverse correlation with MPR $(r=-0.41$ and -0.49 , respectively; $P<0.05)$ but not with IVUS measurements. MPR correlated inversely with plaque volume index $(r=-0.40$, $P<0.05)$ but not with maximal luminal stenosis as assessed by IVUS. In addition, MPR and IVUS measurements gradually inversely changed after heart transplantation (all $P<0.05$ ). Conclusion: This study confirms that CAV is a progressive process, diffusely involving the epicardial and microvascular coronary system. Plaque burden as determined by IVUS agrees well with MPR as assessed by PET in recipients with normal

Received Dec. 14, 2009; revision accepted Feb. 17, 2010.

For correspondence or reprints contact: Chii-Ming Lee, Division of Cardiology, Department of Internal Medicine, National Taiwan University Hospital, National Taiwan University College of Medicine, No. 7, Chung-

Shan South Rd., Taipei, 10002, Taiwan.

E-mail: chiiminglee@ntu.edu.tw

COPYRIGHT () 2010 by the Society of Nuclear Medicine, Inc. coronary angiography results. This finding suggests that dynamic ${ }^{13} \mathrm{~N}$-ammonia PET is clinically feasible for the early detection of CAV and can be used as a reliable marker of disease progression.

Key Words: cardiac allograft vasculopathy; transplantation; positron emission tomography; myocardial perfusion quantification

J Nucl Med 2010; 51:906-912

DOI: 10.2967/jnumed.109.073833

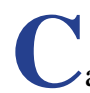
ardiac allograft vasculopathy (CAV) is one of the leading causes of late mortality after heart transplantation $(1,2)$. Early CAV is clinically silent, and ischemia is usually not evident until the disease is far advanced. The traditional annual coronary angiogram for surveillance is of limited value because CAV is characterized by diffuse concentric intimal thickening of both epicardial and intramyocardial arteries and may thus be overlooked on a coronary angiogram. Intravascular ultrasound (IVUS) has been proposed to be the most sensitive method for diagnosis of early CAV (3-8). However, the invasiveness and the physical bulkiness of IVUS catheters make the widespread application of IVUS in the detection of CAV difficult (2-5).

Stress myocardial perfusion images, including SPECT and PET, have been recognized as key diagnostic methods to evaluate coronary artery disease (9-12). Stress myocardial SPECT, in comparison with invasive coronary angiography, frequently underestimates the extent and severity of CAV (8,13-16). Recently, PET has come to be considered the noninvasive gold standard. By quantification of the absolute myocardial blood flow (MBF) during stress and rest, the myocardial perfusion reserve (MPR) can be deduced to 
represent the epicardial arteries or microvascular dysfunction (17-20). Several studies involving patients with progressive coronary artery disease (21-23), idiopathic cardiomyopathies (24), and hypertrophic cardiomyopathies (25) have suggested the prognostic value of quantitative PET. However, for cardiac transplantation recipients, MPR measured by PET has been tested in only a few studies $(26,27)$. A few previous studies have yielded conflicting results in Dopplerderived coronary flow reserve and morphologic change in CAV (28-34). In addition, the impact of MPR by dynamic PET on the prediction of graft failure is still inconclusive. Therefore, we sought to compare myocardial perfusion and MPR assessed by dynamic adenosine ${ }^{13} \mathrm{~N}$-ammonia PET and coronary morphologic changes measured by IVUS in angiographically normal cardiac transplant recipients, to test the value in detecting early stages of CAV.

\section{MATERIALS AND METHODS}

Between January 2007 and May 2009, 27 consecutive recipients (20 men and 7 women; mean age \pm SD, $46 \pm 12$ y) who had normal coronary angiography findings $(7,8)$ and normal left ventricular systolic function (ejection fraction $\geq 60 \%$ ) were enrolled at $2.5 \pm 2.1$ y (range, $1-9.5$ y) after cardiac transplantation. For each recipient, PET and echocardiography were performed within 1 mo of the invasive coronary angiography and IVUS examination. The protocol was approved by the institutional review board, and written informed consent was obtained from each patient before enrollment.

\section{IVUS}

After the diagnostic coronary angiography, 5,000 $\mathrm{U}$ of intravenous heparin were administered and a 6-F guiding catheter was inserted in the left main coronary artery. The IVUS catheter (Atlantis SR Pro 2.5F, 40-MHz; Boston Scientific) was advanced so that the IVUS transducer was positioned at the distal left anterior descending coronary artery (LAD). The motorized IVUS transducer was pulled back at a constant rate of $1 \mathrm{~mm} / \mathrm{s}$ along the length $(\geq 50 \mathrm{~mm})$ of the vessel to the ostium of the left main coronary artery. Two experienced readers, who did not know the PET findings, were responsible for analyzing the IVUS records using the resident software (Galax system; Boston Scientific). The plaque volume index was quantitatively measured according to the method of Pethig et al. (30), with slight modifications $(7,8)$. In brief, serial cross-sectional areas (in $\mathrm{mm}^{2}$ ) of lumen and vessel, defined as the areas within the intimal border and within the external elastic membrane, respectively, were determined every $2 \mathrm{~mm}$ along the entire length assessed. The plaque area was defined as the vessel minus the lumen. The percentage of area stenosis was then calculated as (plaque area/vessel) $\times 100 \%$. The luminal, vessel, and plaque volumes (in $\mathrm{mm}^{3}$ ) of each segment were calculated as cross-sectional areas (lumen, vessel, and plaque areas) $\times$ segment length of $2 \mathrm{~mm}$. Total volumes of lumen, vessel, and plaque were obtained by adding the measurements of all vascular segments. A plaque volume index, defined as (total plaque volume/total vessel volume) $\times 100$, was used to normalize the individual variations in the vessel and in the vessel length as assessed by IVUS.

\begin{tabular}{|c|c|}
\hline Characteristic & Data \\
\hline \multicolumn{2}{|l|}{ Recipient age (y) } \\
\hline Mean $\pm S D$ & $46 \pm 12$ \\
\hline Range & $22-67$ \\
\hline Male sex $(n)$ & $20(74 \%)$ \\
\hline \multicolumn{2}{|l|}{ Posttransplant years } \\
\hline Mean $\pm S D$ & $2.5 \pm 2.1$ \\
\hline Range & $1-9.5$ \\
\hline Hypertension (n) & $5(19 \%)$ \\
\hline Diabetes mellitus $(n)$ & $8(30 \%)$ \\
\hline Hyperlipidemia/statin (n) & $5(19 \%)$ \\
\hline \multicolumn{2}{|l|}{ Pretransplant diagnosis $(n)$} \\
\hline Coronary artery disease & $10(37 \%)$ \\
\hline Dilated cardiomyopathy & $15(56 \%)$ \\
\hline Myocarditis & $2(7 \%)$ \\
\hline
\end{tabular}

PET

${ }^{13} \mathrm{~N}$-ammonia PET was performed at rest and during adenosine stress at a standard rate $(0.14 \mathrm{mg} / \mathrm{min} / \mathrm{kg}$ of body weight $)$ over $6 \mathrm{~min}$, as previously reported (35). Individual patients received a 740 - to $925-\mathrm{MBq}$ injection of ${ }^{13} \mathrm{~N}$-ammonia into a peripheral vein over $30 \mathrm{~s}$ by a volumetric pump. Images were acquired in 2-dimensional mode on an Advance PET scanner (GE Healthcare), within a field of view between 14.45 and $15.7 \mathrm{~cm}$. The optimal imaging position was determined on a 2-min short transmission scan with an external ${ }^{68} \mathrm{Ge}$ source. Dynamic emission scans were obtained using a standard protocol consisting of $12 \times 10$-s, $4 \times 15$-s, $4 \times 30$-s, and $3 \times 300$-s frames and a matrix of $128 \times 128$, followed by reconstruction using ordered-subset expectation maximization. Transmission scanning for photon attenuation correction was performed with an external ${ }^{68} \mathrm{Ge}$ source. The PET datasets were moved to a Xeleris workstation (GE Healthcare) by DICOM transfer. For review, the images were resliced in short-axis and vertical and horizontal long-axis orientations.

\section{PET Data Analysis}

Regional ${ }^{13} \mathrm{~N}$-ammonia PET results were assessed using a 17 segment model and a semiquantitative scoring system of the severity and extent of the defect, as recommended by the American Heart Society of Nuclear Cardiology $(9,36,37)$. Each segment was scored using a 5-point system based on the severity of tracer uptake $(0=$ normal, $1=$ equivocal, $2=$ moderate, $3=$ severe, and $4=$ apparent absence of tracer uptake). Summed scores were calculated from these segmental scores, including a summed rest score (the sum of the 17 segmental rest scores) and summed stress score (the sum of the 17 segmental stress scores). A summed difference score (the difference between summed stress and rest scores) was calculated. The extent of ischemia was expressed as the percentage of ischemic myocardium (summed difference score $/ 68 \times 100$ ): $<2.5 \%$ was considered nonischemic, $2.5 \%-8 \%$ was considered slight to moderate ischemia, and $\geq 8 \%$ was considered extensive ischemia, as modified from Zellweger et al. (38). PET image interpretation according to these definitions was performed by 2 experienced readers who had no access to the IVUS records. Diverging interpretations were classified by consensus. Quantitative MBF at rest and during adenosine stress was determined using ${ }^{13} \mathrm{~N}$-ammonia PET. Previously validated compartmental modeling techniques were 


\begin{tabular}{|c|c|c|c|c|}
\hline Parameter & LAD & LCX & RCA & Global \\
\hline \multicolumn{5}{|c|}{ MBF (mL/min/g) } \\
\hline Rest & $0.94 \pm 0.18(0.55-1.32)$ & $1.17 \pm 0.23(0.75-1.80)$ & $0.98 \pm 0.19(0.51-1.39)$ & $0.94 \pm 0.18(0.58-1.38)$ \\
\hline Hyperemia & $2.43 \pm 0.62(1.28-3.41)$ & $2.71 \pm 0.64(1.51-4.11)$ & $2.46 \pm 0.70(1.07-3.80)$ & $2.30 \pm 0.56(1.16-3.42)$ \\
\hline MPR & $2.67 \pm 0.90(1.39-5.52)$ & $2.41 \pm 0.80(1.26-4.53)$ & $2.63 \pm 1.22(1.26-7.47)$ & $2.54 \pm 0.92(1.39-5.51)$ \\
\hline
\end{tabular}

applied to the time-activity curves to obtain regional estimates of MBF ( $\mathrm{mL} / \mathrm{g} / \mathrm{min}$ ) (39) using the PMOD software package (version 2.8; PMOD Technologies Ltd.) (23). MPR was calculated as the ratio of hyperemic to resting $\mathrm{MBF}$, and values of 2.0 or more were considered normal (40).

\section{Statistical Analysis}

Data were expressed as mean $\pm \mathrm{SD}$. Comparisons were made using the Student test for continuous variables and $\chi^{2}$ analysis for categoric variables. ANOVA was performed to detect any associations between 2 or more variables. IVUS measurements were compared with PET variables by linear regression analysis. All analyses were performed using STATA (release 10.0; StataCorp LP) statistical software. All statistical tests were 2-sided, and a $P$ value of less than 0.05 was considered statistically significant.

\section{RESULTS}

A total of 27 cardiac transplant recipients with patent coronary angiograms were included in the study. Relevant baseline characteristics of the patients are reported in Table 1. All patients received standard immunosuppressive therapy as previously described $(7,8,13-15)$. Based on concurrent endomyocardial biopsy findings, none had acute rejection of grade II or higher (according to the system of the International Society for Heart and Lung Transplantation) during the IVUS study (41).

IVUS and PET were successfully performed on all 27 patients, and no complications occurred. The mean and maximal plaque indices of LAD as assessed by IVUS were $27.82 \pm 12.33 \mathrm{~mm}^{3}$ (range, $7.11-50.13 \mathrm{~mm}^{3}$ ) and $44.57 \pm$

FIGURE 1. Quantitative and qualitative assessment by rest/adenosine stress ${ }^{13} \mathrm{~N}$-ammonia PET of $57-y$-old man who had received orthotopic heart transplant 4 y previously. Polar maps and bar chart of absolute MBF in dynamic images (top) show regional perfusion heterogeneity, and qualitative static images normalized to individual left ventricular maximum (bottom) show significant reduction of stress flow, resulting in blunted flow reserve.

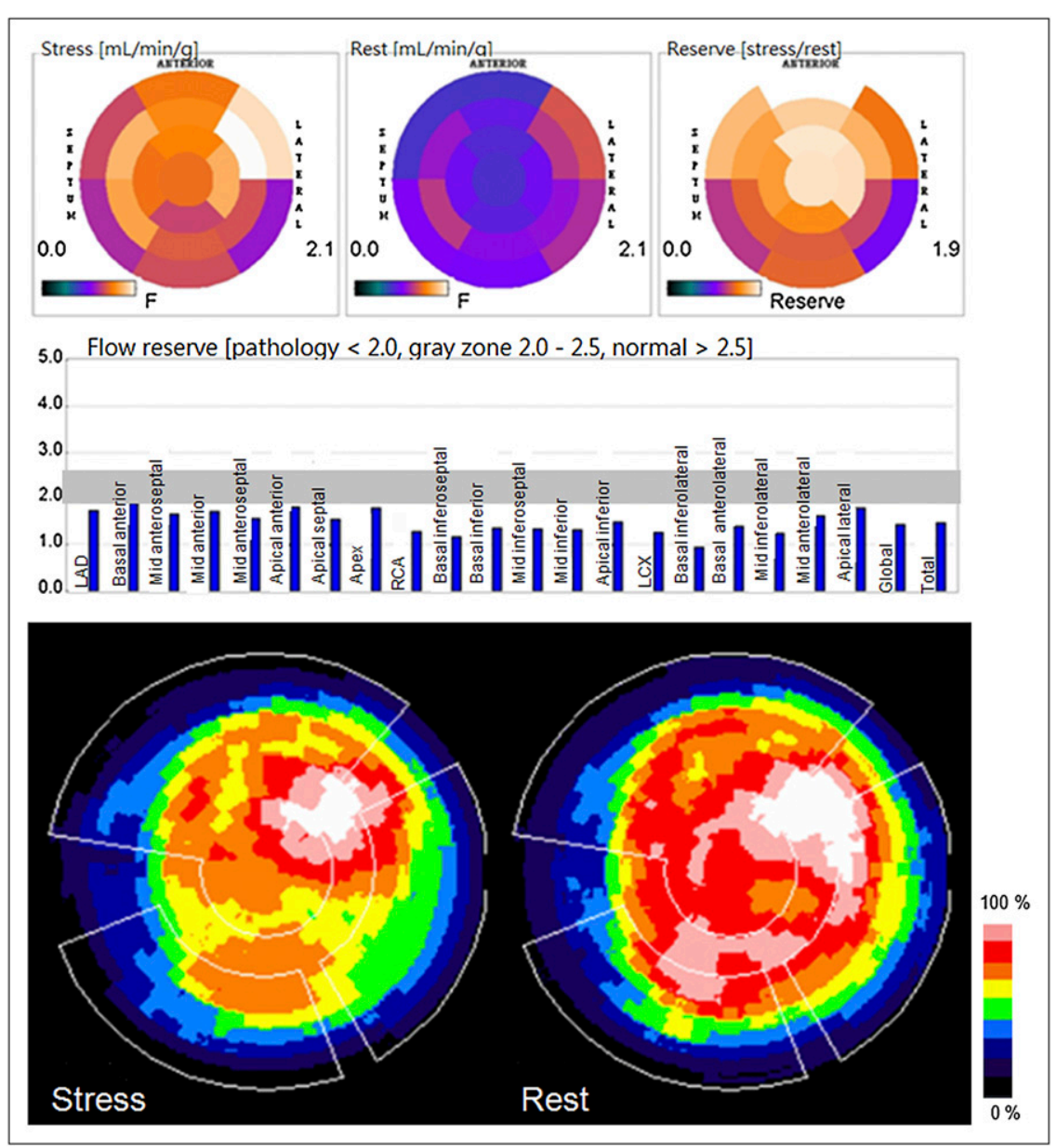




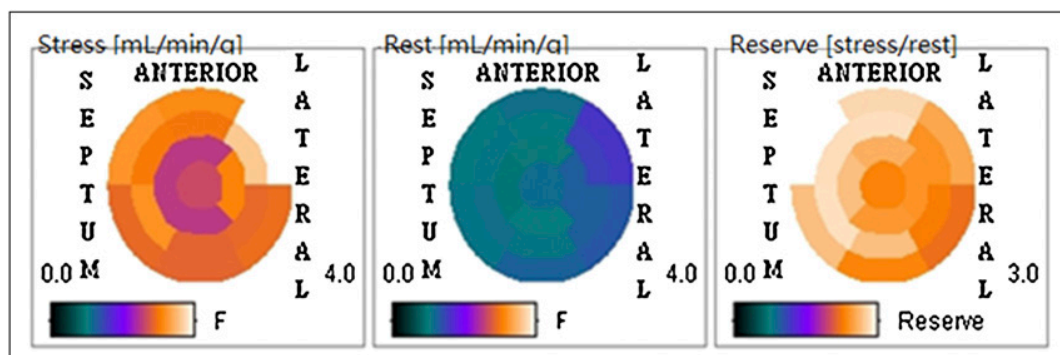

Flow reserve [pathology $<2.0$, red box $2.0-2.5$, normal $>2.0$ ]
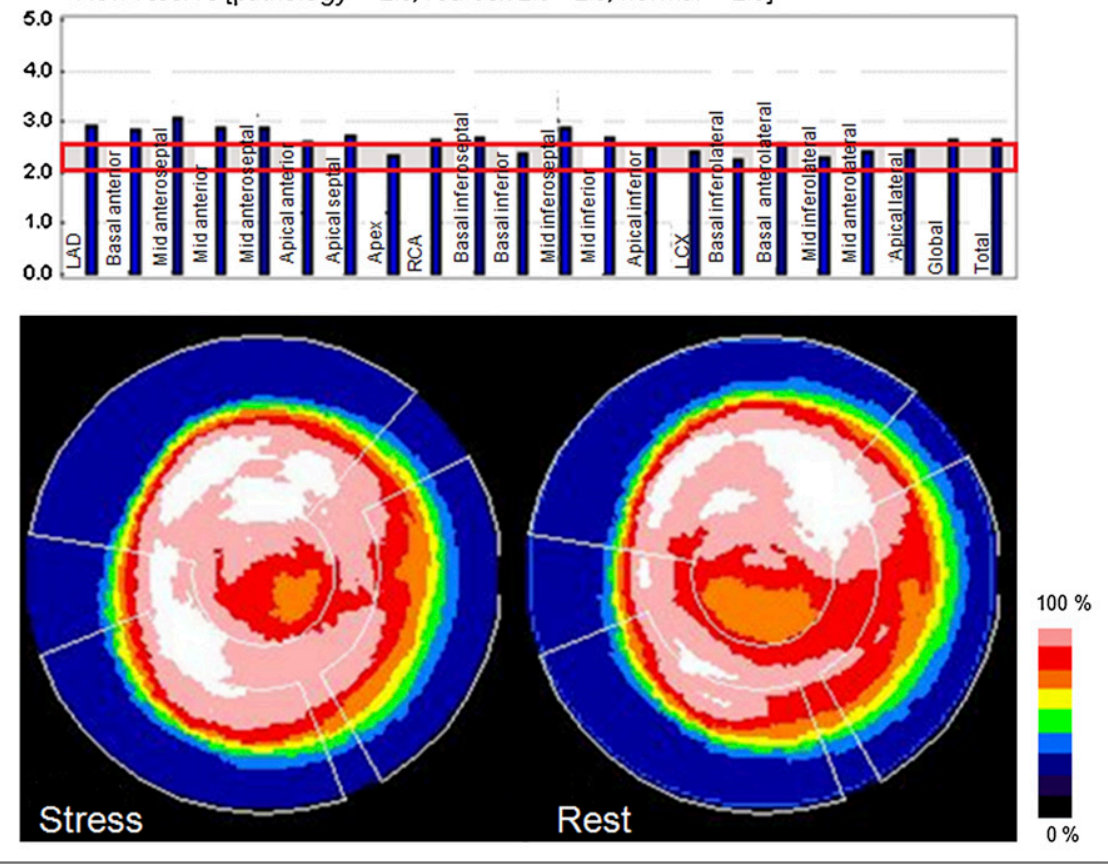

FIGURE 2. ${ }^{13} \mathrm{~N}$-ammonia PET study of 54-y-old man who had received orthotopic heart transplant 1 y previously shows normal flow reserve in dynamic images (top) and no significant perfusion heterogeneity in qualitative static images (bottom).
$17.31 \mathrm{~mm}^{3}$ (range, $16.14-77.92 \mathrm{~mm}^{3}$ ), respectively. By semiquantitative PET analysis, the summed stress score, summed rest score, and summed difference score were $2.0 \pm 2.3$ (range, $0-10$ ), $0.8 \pm 0.7$ (range, $0-2$ ), and $1.2 \pm$ 2.0 (range, 0-9), respectively. The distribution of patients based on the extent of ischemia was $20(74 \%), 3(11 \%), 3$ $(11 \%)$, and $1(4 \%)$ for no ischemia, slight ischemia, moderate ischemia, and extensive ischemia, respectively. MBF at rest or during adenosine stress, and the MPR of the LAD distribution, correlated strongly between the other 2 coronary artery distribution territories $(r \geq 0.97, P<$ 0.0001 , Table 2), suggesting that CAV involved the 3 major coronary arteries to a similar degree. Representative images of quantitative and qualitative assessment by rest and adenosine stress ${ }^{13} \mathrm{~N}$-ammonia PET are shown in Figures 1 and 2 .

There were moderate inverse correlations between summed stress score, summed difference score, and the MPR of the global myocardium $(r=-0.41$ and -0.49 , respectively; $P<0.05$ ) but not IVUS parameters. There was no significant correlation between IVUS parameters and MBF at rest. In contrast, stress MBF and MPR correlated inversely with plaque volume index measured by IVUS (both $r=-0.40$ in LAD territory, whereas $r=-0.46$ and -0.36 , respectively, in global myocardium; all $P<0.05$ ) but not maximal luminal stenosis (Fig. 3). In the 20 cases regarded as nonischemic by semiquantitative PET analysis, a global myocardium MPR of 2 or more in 4 subjects (20\%) was noted, suggesting diffuse coronary lesions with balanced ischemia.

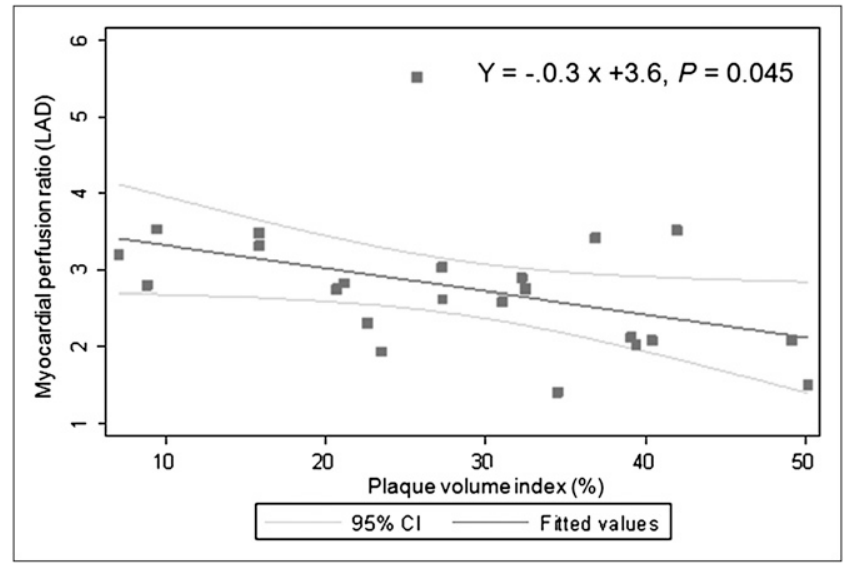

FIGURE 3. Correlation between myocardial perfusion ratio as assessed by PET and plaque volume index as measured by IVUS. 

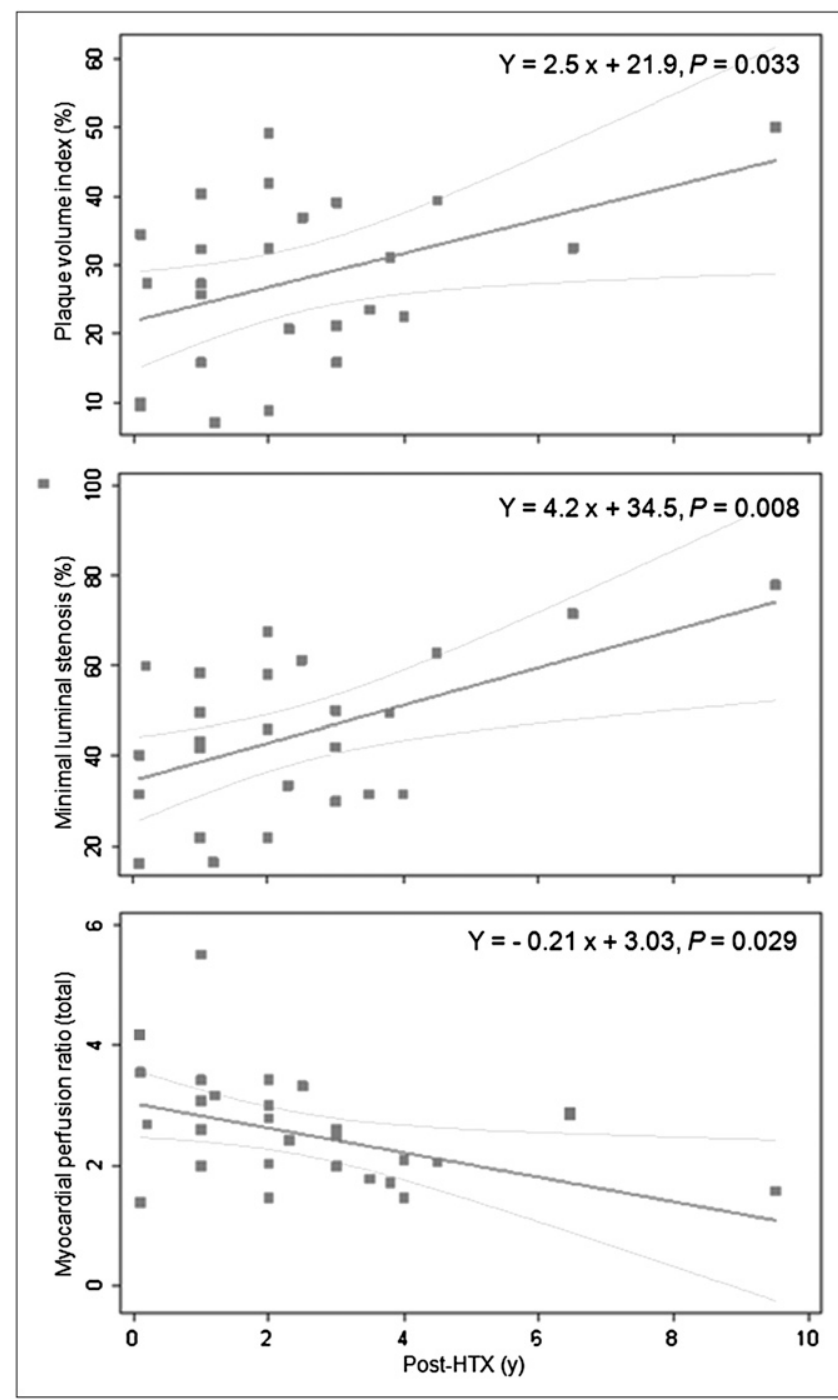

FIGURE 4. Correlations between plaque volume index (top), maximal luminal stenosis (middle), and myocardial perfusion ratio (bottom) and time after heart transplantation.

Furthermore, we compared the patient characteristics with the results of PET or IVUS. With the exception of posttransplantation time, no significant correlations were found between clinical characteristics (including pretransplantation diagnosis, diabetes mellitus, hypertension, hyperlipidemia, sex or age, or number of cardiac risk factors) and PET or IVUS parameters. Although the coronary angiograms showed patency for all subjects, the MPR of the LAD territory or global myocardium deteriorated, and IVUS parameters (both plaque volume index and maximal luminal stenoses) increased as the time after heart transplantation increased (all $P<0.05$ ) (Fig. 4).

\section{DISCUSSION}

Because of the low sensitivity of coronary angiography, IVUS and Doppler-derived coronary flow reserve have been considered the standards in the diagnosis of CAV (1-3).
However, clinical application is limited because the procedure is invasive and time-consuming and requires highly trained medical personnel. The current study demonstrated that the vasodilation capacity and perfusion abnormalities detected by PET correlated well with the coronary morphologic changes in IVUS.

The main advantage of PET is its superior spatial resolution and the possibility of noninvasive assessment of absolute quantitative MBF, from which MPR can be calculated. The assessment of quantitative regional MBF and MPR with ${ }^{13} \mathrm{~N}$-ammonia PET has been well established. ${ }^{13} \mathrm{~N}$-ammonia dynamic PET blood flow measurements include integrated vasodilation capacity, endothelium-related vasomotor function, and epicardial conduit vessel function (42,43). MBF and MPR not only can provide important diagnostic and prognostic information $(10-12,20-25)$ but also can be used as a surrogate endpoint to assess therapeutic response (44-48) and to guide interventions aimed at reducing cardiac risks or ischemic burden in subjects with native coronary artery disease (49).

$\mathrm{CAV}$ is a progressive process involving the epicardial and microvascular coronary systems. Conflicting results in IVUS- and Doppler-derived coronary flow reserve studies $(7,8,28-34,50-52)$ suggest that the correlation between endothelial dysfunction and coronary changes is complex. Studies in the past have shown that dynamic PET provides information complementary to coronary anatomy. By using dipyridamole ${ }^{13} \mathrm{~N}$-ammonia PET, Preumont et al. (27) found that MBF reserve was impaired early after heart transplantation and restored within $1 \mathrm{y}$ in heart transplant recipients free of allograft rejection and with normal coronary angiography findings. Allen-Auerbach et al. (26) found that the degree of vasodilatory capacity detected by PET is associated with morphologic indices of disease progression as assessed by IVUS at 1-2 y after transplantation. However, the sample sizes were rather small, and posttransplantation durations were short. Whether dynamic PET is enough to assess patients at risk of CAV remains to be determined.

Consistent with previous reports, our study confirmed that semiquantitative ${ }^{13} \mathrm{~N}$-ammonia PET is superior to invasive coronary angiography in the detection of CAV. Through the use of dynamic PET, an additional 20\% of subjects who had normal semiquantitative PET results were found to have impaired coronary flow reserve. Moreover, the severity of the impairment inversely correlated with the coronary plaque burden as assessed by IVUS. This finding demonstrated the superiority of coronary flow reserve over perfusion scans alone, partly because CAV involves multiple vessels so that regional perfusion abnormalities could be masked by diffuse lesions with balanced ischemia on qualitative images. Therefore, dynamic ${ }^{13} \mathrm{~N}$-ammonia PET is a better, more reliable noninvasive tool for the detection of early CAV and disease progression. A preserved coronary flow reserve as assessed by dynamic PET may obviate 
invasive coronary angiography and IVUS surveillance in transplant recipients.

The study had some limitations. First, the number of recipients included was small, and they were heterogeneous in coronary risk factors, donor age, immunosuppressive protocols, and history of myocardial rejections. Second, in this cross-section study, not all patients underwent IVUS immediately after transplantation; therefore, it is difficult to differentiate donor-transmitted coronary artery disease from CAV. In addition, there is not a clear MPR cutoff value to recognize more altered vessels, and the predictive value of ${ }^{13} \mathrm{~N}$-ammonia PET for long-term clinical outcome is not yet known. A large-scale prospective study of serial quantitative IVUS and PET measurements to assess the progression of CAV and to elucidate the prognostic value of quantitative PET in posttransplant recipients is needed.

\section{CONCLUSION}

Using noninvasive ${ }^{13} \mathrm{~N}$-ammonia PET, this study confirmed that CAV is a progressive and diffuse process involving the epicardial and microvascular coronary system. There is good agreement between plaque burden as determined by IVUS and MPR as assessed by PET in recipients with normal coronary angiography findings. The findings of this study suggest that quantitative measurement of myocardial flow using dynamic ${ }^{13} \mathrm{~N}$-ammonia PET is clinically feasible for the early detection of CAV and could be used as a reliable marker of disease progression.

\section{ACKNOWLEDGMENTS}

We thank Chien-Chung Chen for technical assistance. This work was supported in part by grant NTUH-97-S852 from the National Taiwan University Hospital, Taiwan, and NSC 98-2314-B-002-145-MY2 from the National Science Council of Taiwan.

\section{REFERENCES}

1. Schmauss D, Weis M. Cardiac allograft vasculopathy: recent developments. Circulation. 2008;117:2131-2141.

2. Kass M, Allan R, Haddad H. Diagnosis of graft coronary artery disease. Curr Opin Cardiol. 2007;22:139-145.

3. Johnson DE, Aldermann EL, Scroeder JS, et al. Transplant coronary artery disease: histopathologic correlations with angiographic morphology. J Am Coll Cardiol. 1991;17:449-457.

4. St. Goar FG, Pinto FJ, Aldermann EL, et al. Intracoronary ultrasound in cardial transplant recipients: in vivo evidence of angiographically silent intimal thickening. Circulation. 1992;85:979-987.

5. Spes CH, Klauss V, Rieber J, et al. Functional and morphological findings in heart transplant recipients with a normal coronary angiogram: an analysis by dobutamine stress echocardiography, intracoronary Doppler and intravascular ultrasound. J Heart Lung Transplant. 1999;18:391-398.

6. Stork S, Behr TM, Birk M, et al. Assessment of cardiac allograft vasculopathy late after heart transplantation: when is coronary angiography necessary? $J$ Heart Lung Transplant. 2006;25:1103-1175.

7. Lee $\mathrm{CM}$, Wu $\mathrm{YW}$, Chou NK, et al. Intravascular ultrasound evidence of angiographically silent allograft vasculopathy inversely correlates with circulating level of hepatocyte growth factor. J Heart Lung Transplant. 2006;25:14561461 .
8. Lee CM, Wu YW, Jui HY, et al. Intravascular ultrasound correlates with coronary flow reserve and predicts the survival in angiographically silent cardiac transplant recipients. Cardiology. 2008;109:93-98.

9. Hendel RC, Berman DS, Di Carli MF, et al. ACCF/ASNC/ACR/AHA/ASE/ SCCT/SCMR/SNM 2009 appropriate use criteria for cardiac radionuclide imaging: a report of the American College of Cardiology Foundation Appropriate Use Criteria Task Force, the American Society of Nuclear Cardiology, the American College of Radiology, the American Heart Association, the American Society of Echocardiography, the Society of Cardiovascular Computed Tomography, the Society for Cardiovascular Magnetic Resonance, and the Society of Nuclear Medicine: endorsed by the American College of Emergency Physicians. Circulation. 2009;119:e561-e587.

10. Shaw LJ, Narula J. Risk assessment and predictive value of coronary artery disease testing. J Nucl Med. 2009;50:1296-1306.

11. Di Carli MF, Hachamovitch R. New technology for noninvasive evaluation of coronary artery disease. Circulation. 2007;115:1464-1480.

12. Bengel FM, Higuchi T, Javadi MS, Lautamäki R. Cardiac positron emission tomography. J Am Coll Cardiol. 2009;54:1-15.

13. Yen RF, Ho YL, Chou NK, Hsu RB, Huang PJ. Inhomogeneity of myocardial perfusion in heart transplant recipients: evaluation with dobutamine thallium-201 SPECT. Nucl Med Commun. 2001;22:1015-1019.

14. Wu YW, Yen RF, Lee CM, et al. Usefulness of progressive inhomogeneity of myocardial perfusion and chronotropic incompetence in detecting cardiac allograft vasculopathy: evaluation with dobutamine thallium-201 myocardial SPECT. Cardiology. 2005;104:156-161.

15. Wu YW, Yen RF, Lee CM, et al. Diagnostic and prognostic value of dobutamine thallium-201 single-photon emission computed tomography after heart transplantation. J Heart Lung Transplant. 2005;24:544-550.

16. Puskás C, Kosch M, Kerber S, et al. Progressive heterogeneity of myocardial perfusion in heart transplant recipients detected by thallium-201 myocardial SPECT. J Nucl Med. 1997;38:760-765.

17. Muzik O, Beanlands RS, Hutchins GD, et al. Validation of nitrogen-13-ammonia tracer kinetic model for quantification of myocardial blood flow using PET. J Nucl Med. 1993;34:83-91.

18. Uren NG, Melin JA, De Bruyne B, et al. Relation between myocardial blood flow and the severity of coronary-artery stenosis. N Engl J Med. 1994;330:17821788 .

19. Kaufmann PA, Camici PG. Myocardial blood flow by PET: technical aspects and clinical applications. J Nucl Med. 2005;46:75-88.

20. Graf S, Khorsand A, Gwechenberger M, et al. Typical chest pain and normal coronary angiogram: cardiac risk factor analysis versus PET for detection of microvascular disease. J Nucl Med. 2007;48:175-181.

21. Sdringola S, Loghin C, Boccalandro F, Gould KL. Mechanisms of progression and regression of coronary artery disease by PET related to treatment intensity and clinical events at long-term follow-up. J Nucl Med. 2006;47:59-67.

22. Tio RA, Dabeshlim A, Siebelink H-MJ, et al. Comparison between the prognostic value of left ventricular function and myocardial perfusion reserve in patients with ischemic heart disease. J Nucl Med. 2009;50:214-219.

23. Herzog BA, Husmann L, Valenta I, et al. Long-term prognostic value of ${ }^{13} \mathrm{~N}-$ ammonia myocardial perfusion positron emission tomography: added value of coronary flow reserve. J Am Coll Cardiol. 2009;54:150-156.

24. Neglia D, Michelassi C, Trivieri MG, et al. Prognostic role of myocardial blood flow impairment in idiopathic left ventricular dysfunction. Circulation. 2002; 105:186-193.

25. Cecchi F, Olivotto I, Gistri R, Lorenzoni R, Chiriatti G, Camici PG. Coronary microvascular dysfunction and prognosis in hypertrophic cardiomyopathy. $N$ Engl J Med. 2003;349:1027-1035.

26. Allen-Auerbach M, Schöder H, Johnson J, et al. Relationship between coronary function by positron emission tomography and temporal changes in morphology by intravascular ultrasound (IVUS) in transplant recipients. J Heart Lung Transplant. 1999;18:211-219.

27. Preumont N, Berkenboom G, Vachiery J, et al. Early alterations of myocardial blood flow reserve in heart transplant recipients with angiographically normal coronary arteries. J Heart Lung Transplant. 2000;19:538-545.

28. Klauss V, Ackermann K, Henneke KH, et al. Epicardial intimal thickening in transplant coronary artery disease and resistance vessel response to adenosine: a combined intravascular ultrasound and Doppler study. Circulation. 1997; 96(suppl):II-159-II-164.

29. Kofoed KF, Czernin J, Johnson J, et al. Effects of cardiac allograft vasculopathy on myocardial blood flow, vasodilatory capacity, and coronary vasomotion. Circulation. 1997;95:600-606.

30. Pethig K, Heublein B, Meliss RR, Haverich A. Volumetric remodeling of the proximal left coronary artery: early versus late after heart transplantation. $J \mathrm{Am}$ Coll Cardiol. 1999;34:197-203. 
31. Fearon WF, Nakamura M, Lee DP, et al. Simultaneous assessment of fractional and coronary flow reserves in cardiac transplant recipients: Physiologic Investigation for Transplant Arteriopathy (PITA study). Circulation. 2003;108: 1605-1610.

32. Fearon WF, Hirohata A, Nakamura M, et al. Discordant changes in epicardial and microvascular coronary physiology after cardiac transplantation: Physiologic Investigation for Transplant Arteriopathy II (PITA II) study. J Heart Lung Transplant. 2006;25:765-771.

33. Rodrigues AC, Frimm Cde C, Bacal F, et al. Coronary flow reserve impairment predicts cardiac events in heart transplant patients with preserved left ventricular function. Int J Cardiol. 2005;103:201-206.

34. Schubert S, Abdul-Khaliq H, Wellnhofer E, et al. Coronary flow reserve measurement detects transplant coronary artery disease in pediatric heart transplant patients. J Heart Lung Transplant. 2008;27:514-521.

35. Jorg-Ciopor M, Namdar M, Turina J, et al. Regional myocardial ischemia in hypertrophic cardiomyopathy: impact of myectomy. J Thorac Cardiovasc Surg. 2004;128:163-169.

36. Machac J, Bacharach SL, Bateman TM, et al. Positron emission tomography myocardial perfusion and glucose metabolism imaging. J Nucl Cardiol. 2006;13: e121-e151.

37. Cerqueira MD, Weissman NJ, Dilsizian V, et al. Standardized myocardial segmentation and nomenclature for tomographic imaging of the heart: a statement for healthcare professionals from the Cardiac Imaging Committee of the Council on Clinical Cardiology of the American Heart Association. Circulation. 2002;105:539-542.

38. Zellweger MJ, Hachamovitach R, Kang X, et al. The threshold, incidence, and predictors of prognostically high-risk silent ischemia in asymptomatic patients without prior diagnosis of coronary artery disease. J Nucl Cardiol. 2009;16:193-200.

39. DeGrado TR, Hanson MW, Turkington TG, et al. Myocardial blood flow estimation for longitudinal studies using ${ }^{13} \mathrm{~N}$-ammonia and PET. J Nucl Cardiol. 1996;3:494-507.

40. Camici PG, Crea F. Coronary microvascular dysfunction. N Engl J Med. 2007; 356:830-840.

41. Billingham ME, Cary NR, Hammond ME, et al. A working formulation for the standardization of nomenclature in the diagnosis of heart and lung rejection: Heart Rejection Study Group. The International Society for Heart Transplantation. J Heart Transplant. 1990;9:587-593.
42. Schelbert HR, Phelps ME, Huang SC, et al. N-13 ammonia as an indicator of myocardial blood flow. Circulation. 1981;63:1259-1272.

43. Hutchins GD, Schwaiger M, Rosenspire KC, Krivokapich J, Schelbert H, Kuhl DE. Noninvasive quantification of regional blood flow in the human heart using $\mathrm{N}-13$ ammonia and dynamic positron emission tomographic imaging. J Am Coll Cardiol. 1990;15:1032-1042.

44. Gould KL, Martucci JP, Goldberg DI, et al. Short-term cholesterol lowering decreases size and severity of perfusion abnormalities by positron emission tomography after dipyridamole in patients with coronary artery disease. Circulation. 1994;89:1530-1538.

45. Sdringola S, Nakagawa K, Nakagawa Y, et al. Combined intense lifestyle and pharmacologic lipid treatment further reduce coronary events and myocardial perfusion abnormalities compared with usual-care cholesterol-lowering drugs in coronary artery disease. J Am Coll Cardiol. 2003;41:263-272.

46. Wielepp P, Baller D, Gleichmann U, Pulawski E, Horstkotte D, Burchert W. Beneficial effects of atorvastatin on myocardial regions with initially low vasodilatory capacity at various stages of coronary artery disease. Eur J Nucl Med Mol Imaging. 2005;32:1371-1377.

47. Higuchi T, Abletshauser C, Nekolla SG, Schwaiger M, Bengel FM. Effect of the angiotensin receptor blocker Valsartan on coronary microvascular flow reserve in moderately hypertensive patients with stable coronary artery disease. Microcirculation. 2007;14:805-812.

48. Sdringola S, Gould KL, Zamarka LG, McLain R, Garner J. A 6 month randomized, double blind, placebo controlled, multi-center trial of high dose atorvastatin on myocardial perfusion abnormalities by positron emission tomography in coronary artery disease. Am Heart J. 2008;155:245-253.

49. Siegrist PT, Husmann L, Knabenhans $\mathrm{M}$, et al. ${ }^{13} \mathrm{~N}$-ammonia myocardial perfusion imaging with a PET/CT scanner: impact on clinical decision making and cost-effectiveness. Eur J Nucl Med Mol Imaging. 2008;35: 889-895.

50. Hirohata A, Nakamura M, Waseda $\mathrm{K}$, et al. Changes in coronary anatomy and physiology after heart transplantation. Am J Cardiol. 2007;99:1603-1607.

51. Fearon WF, Potena L, Hirohata A, et al. Changes in coronary arterial dimensions early after cardiac transplantation. Transplantation. 2007;83:700-705.

52. Sakurai R, Yamasaki M, Nakamura M, et al. Determinants of lumen loss between years 1 and 2 after cardiac transplantation. Transplantation. 2007;84: 1097-1102. 